C 2015 The Author. Metaphilosophy published by Metaphilosophy LLC and John Wiley \&

Sons Ltd

METAPHILOSOPHY

Vol. 46, Nos. 4-5, October 2015

0026-1068

\title{
HOW DISTINCTIVE IS PHILOSOPHERS’ INTUITION TALK?
}

\author{
JAMES ANDOW
}

\begin{abstract}
The word "intuition" is one frequently used in philosophy. It is often assumed that the way in which philosophers use the word, and others like it, is very distinctive. This claim has been subjected to little empirical scrutiny, however. This article presents the first steps in a qualitative analysis of the use of intuition talk in the academy. It presents the findings of two preliminary empirical studies. The first study examines the use of intuition talk in spoken academic English. The second examines the use of intuition talk in written academic English. It considers what these studies tell us about the distinctiveness of philosophical language and methods and considers some implications for evaluative and ameliorative methodology.
\end{abstract}

Keywords: metaphilosophy, sociology of philosophy, intuitions, philosophical methods, English for academic purposes, descriptive methodology.

\section{Introduction}

The word "intuition" is one frequently used in philosophy. It is often assumed that the way in which philosophers use the word, and others like it, is very distinctive. This claim has been subjected to little empirical scrutiny, however. This article presents the first steps in a qualitative analysis of the use of intuition talk in the academy. ${ }^{1}$ The primary aim of the article is descriptive - to gain a better understanding of the language philosophers actually employ. However, such descriptive work is important to philosophical methodology more widely. The structure of the paper is as follows. In section 2, I take some time to motivate the project of descriptive philosophical methodology. I argue that a good understanding of the methods philosophers use is important, or at least helpful, when considering what methods philosophers ought to use, or how philosophers could improve their methods. I also take some time to motivate text-based empirical approaches to descriptive methodology. In section 3, I review the available evidence-from Andow (2015a), Cappelen (2012), and Tallant (2013) — on the use of words like "intuition" in philosophy and other disciplines. In section 4, I present the findings of two preliminary

\footnotetext{
${ }^{1}$ In the remainder of the article, where appropriate, I use the term "intuition talk" or say "words like intuition." The words in question are "intuition," "intuitions," "intuitive," "intuitively," "intuit," "intuits," "counter-intuitive," "counter-intuitively," and so on.
}

(C) 2015 The Author. Metaphilosophy published by Metaphilosophy LLC and John Wiley \& Sons Ltd.

This is an open access article under the terms of the Creative Commons Attribution License, which permits use, distribution and reproduction in any medium, provided the original work is properly cited. 
empirical studies. The first study examines the use of intuition talk in spoken academic English (in Britain). The second examines the use of intuition talk in written academic English (in four disciplines). Finally, in section 5, I consider what these studies tell us about the distinctiveness of philosophical methods and consider some implications for evaluative and ameliorative methodology.

\section{The Importance of Descriptive Methodology}

Over the past few decades interest in philosophical methodology has seen a great surge. One major locus of attention has been the role of intuitions in philosophy (see, e.g., Pust 2014). Another has been the relation between philosophical methods and those of other disciplines (see, e.g., Williamson 2007). These issues can be approached with different types of questions in mind. One regard in which philosophers have been interested in philosophical methods concerns what we may call an evaluative project - they ask evaluative questions, such as whether intuitions are reliable or whether philosophical methods ought to be distinct from those of the sciences. ${ }^{2}$ But this is not the only project. Another is an ameliorative project. Ameliorative questions include, for example, whether there is anything we can do to improve philosophical methods, whether philosophers could fruitfully emulate their scientific colleagues. The final type of project I want to think about here is a descriptive project. The idea of a descriptive project is to provide an accurate picture of what methods philosophers actually use, regardless of whether those methods are any good or could be improved upon. Descriptive methodology is thus interested in questions including the following: Do philosophers use intuitions? If they do, in what ways? And are the methods philosophers use somehow distinctive to philosophy?

There is a sense in which the descriptive project is sensibly considered prior to both the evaluative and the ameliorative projects in methodology. One can ask evaluative and ameliorative questions in isolation from facts about what philosophical methods actually are. If possible, however, it would be more productive to start with a clear answer to the descriptive questions (pace Andow 2015b). If we know first what methods philosophers actually use and how distinctive they are, then we will avoid going astray in our evaluative and ameliorative projects. We will avoid giving negative evaluations of methods that no philosopher ever considered using. And we will avoid suggesting ways to improve upon methods that philosophers simply don't use. In addition, and more importantly, descriptive work, in clarifying and enriching our understanding of philosophical methods, can help us identify productive areas for evaluative and ameliorative work.

\footnotetext{
${ }^{2}$ There is a distinction to be drawn between evaluative and normative considerations, but I won't make it here.
} 
I should make clear that I am not claiming that all work in evaluative and ameliorative methodology has to stop until we have a complete descriptive account of philosophical methods. The risk that methodologists have gone too far astray is probably small (pace Cappelen 2012). The experience of methodologists in philosophy should be expected to equip them with some understanding of the methods philosophers use in their philosophising. Nonetheless, it should be clear that descriptive work is an important complement to the rest of philosophical methodology. Studying philosophers' methods has the potential, for example, to direct methodologists' attention to important aspects of philosophical practice that are not immediately obvious.

It is a shame, then, that most of the methodological literature has proceeded without giving much critical attention to issues in descriptive methodology. In particular, it is a shame that our understanding of philosophical methods is not informed by systematic empirical study. Empirical work has an important role to play in descriptive methodology. Empirical work in evaluative and ameliorative methodology (or at least appeal to relevant empirical literature) is fairly common and widely recognised as important. Experimental philosophers have examined the reliability of various intuitions (see, e.g., Weinberg, Nichols, and Stich 2001). Philosophers interested in gender issues in the profession have identified negative epistemic effects that gender imbalances create and proposed various ameliorative strategies based on empirical research (see, e.g., Stich and Buckwalter 2014 and Saul 2013, and also Antony 2012's worries about Stich and Buckwalter 2014). The importance of empirical work in descriptive methodology has not typically been recognised, however, methodologists being happy, by and large, to proceed with a descriptive understanding of philosophical methods obtained from the armchair.

One way to study the methods of a discipline empirically is to examine the texts they produce. For example, suppose we want to know what role intuitions play in philosophy. One first step might be to ask what philosophers are talking about when they use the word "intuition." Textual analysis has the potential to help us assess claims about what the denotation of "intuition" and its cognates as used by philosophers might be.

\section{Extant Evidence}

To demonstrate the potential of text-based empirical work in descriptive methodology to inform, or reorient, evaluative or ameliorative methodology, we can review some of the extant work in the area. This also helps provide context for the studies I report later in the article. ${ }^{3}$

\footnotetext{
3 One corpus-based study that I won't review in detail, because its concerns are somewhat different, is that of Overton (2013). Overton examines use of "explain" within science journals. A similar study (drawing on grounded theory) was used by Aberdein and Pease in
} 
In this section, I'm going to look at three previous studies: ${ }^{4}$

- Cappelen 2012, which presents an informal study of philosophers' use of intuition talk and compares it to intuition talk in ordinary English.

- Tallant 2013, which presents a study of intuition talk in physics.

- Andow 2015a, in which I present a quantitative diachronic study of intuition talk in the academy over the twentieth century.

One central question, which many have focused on in descriptive philosophical methodology, is whether philosophers rely on intuitions in some distinctive way. Analysis of philosophers' language can speak to this issue. If, on examination, philosophers seem to use intuition talk in a distinctive way_or, as Cappelen puts it, "philosophers have developed an idiolect in which 'intuitive' means something different from what it means in [ordinary] English" $(2012,28)$ - this could provide evidence in support of the claim that there is a distinctive philosophical practice of appealing to intuitions as evidence. ${ }^{5}$ If, on the other hand, it turned out that philosophers' use of intuition talk much resembled non-philosophers' use of intuition talk, then this could serve to undermine the idea. Of course, it depends on exactly the form that the relevant intuition talk takeswhether the usage itself indicates a use of intuitions as evidence rather than in some other role - and textual analysis can help answer questions about that too. Indeed, the upshot of my empirical work reported in later sections suggests that intuitions may play an important role in explanation rather than justification. In any case, this type of inquiry has important implications for those involved in evaluative and ameliorative methodology. For example, on the basis of results we'll review in a moment, Cappelen argues that methodologists have been drastically led astray and that the assumption that philosophers rely on intuitions has "encouraged metaphilosophical pseudo-problems and misleading pictures of what philosophy is and how it is done" (1). He argues that the rejection of this assumption should factor into a drastic reshaping of the way

"An Empirical Investigation into Explanation in Mathematical Conversations," presented at the symposium "Explanation in Mathematics and Ethics" held at Nottingham in 2013.

${ }^{4}$ Another interesting study, which is reported to be a source of some interesting facts about the way intuitions are conceived and the word "intuition" is used in a number of disciplines, is that of Abernathy and Hamm (1995). In 1996, this was claimed to be "the most complete and up-to-date survey of the use of the term 'intuition"” (Hammond 1996, 63). Thanks to Kasaki, who in "Enriching the Framework of Experimental Philosophy" (Kasaki unpublished) draws attention to Hammond 1996.

${ }^{5}$ Cappelen identifies a number of philosophers as assuming that philosophers' use of intuition talk is distinctive in this way, for example: Williamson 2007, 220; Ludwig 2010, 435; and Pust 2000, 30. 
metaphilosophy is done (see 17-21) and in particular moving the focus away from questions about intuitions, what they are, and whether they can be used as evidence.

The first important step in addressing this issue - whether philosophers use intuition talk in a distinctive way-in an empirical way was taken by Cappelen (2012). Cappelen examines the use of intuition talk in ordinary English, asking what sorts of things ordinary uses of "intuitive" and "intuitively" get applied to, what those things have in common, and whether it is plausible that philosophers use the words in the same way. Cappelen summarises his findings about intuition talk in English as follows:

When a speaker of English says "Intuitively, BLAH". . . First, what she says is highly context sensitive and there is no one content that is expressed by such utterances. ... Second, "intuitively" is typically not used to modify propositions or contents. . . Typically it characterizes things like operating systems, dance partnerships, and chess playing. . . . In the occasional cases where "intuitively" does modify a content, it is often used as a hedge, indicating a speaker's weakened commitment to that content. In some cases it is not used simply as a hedge, but also to make explicit that the speaker has not thought carefully about that content - that it is not the result of careful reasoning and that relatively little effort went into the process of reaching that conclusion. (41)

It is worth emphasising Cappelen's second point: that intuition talk is typically not used to modify content in ordinary English. Earlier in the chapter, Cappelen claims: "It is almost impossible to find nonphilosophers describing claims or points as intuitive" (32; my emphasis). Cappelen's observations about unreflective philosophical usage are as follows. First, terms such as "intuition" are used in many different ways by contemporary philosophers - with no agreed paradigms or definitions (59). Second, "intuitively" is much more commonly used by philosophers to modify content than it is to do so by ordinary folk-remarks, ways of stating arguments or points, concepts, and claims can all be intuitive. Third, the main typical unreflective uses of "intuitively, $p$ " border on gibberish (61); no single strategy for charitable reinterpretation works across the board. Some mildly successful (in the sense that they work in a number of cases) strategies include the following: (i) simply remove "intuitively"; (ii) treat the terms as used (usually to hedge) to indicate that a judgement was not reached using elaborate or extensive reasoning; (iii) treat the terms as used (usually to hedge) to indicate that the answer is not a complete answer but intended for quick and easy understanding; and (iv) treat the terms as used to mean something like "pre-theoretic" (which can be a hedge).

While Cappelen's work represents an important first step, there are several limitations to it. Most important, perhaps, with respect to finding 
out whether philosophers' use of intuition talk is distinctive, is the fact that Cappelen contrasts philosophers' use with non-academic use of intuition talk (only one of Cappelen's non-philosophical sources is academic, an article from Heredity). But, of course, what is important with respect to whether philosophers have a distinctive way of using intuitions in their inquiry is a contrast with other academic disciplines. So what we need to be able to do is contrast usage in philosophy with usage in other fields.

The second important step, in this regard, is made by Tallant (2013), who considers the use of intuition talk in another academic discipline. Tallant examines intuition talk in physics and makes the following observations. First, echoing Cappelen's findings about usage elsewhere, Tallant notes that there are many different uses of intuition talk in physics. Second, most commonly contents - results, expectations, explanations, pictures, and understandings - are described as intuitive. Tallant also notes, tentatively, that often being intuitive is taken to be a good thing. ${ }^{6}$ Third, rather less common but still present, is the use of intuition talk to describe arguments, properties, models, and measures. Finally, Tallant notes an interesting, somewhat novel use among physicists: it is not uncommon for physicists to "speak of needing to think about something, or observe matters repeatedly, in order to 'get some intuition' about a subject matter" (2013, 2970-71).

Tallant's work is enlightening. His results suggest a use of intuition talk (and intuitions) in physics that is perhaps surprising both in its extent and in its variety. Tallant doesn't attempt to connect this work to debates about the use of intuitions in philosophy (although see Tallant 2015). The results do suggest, however, that use of intuition talk in philosophy may not be so very distinctive after all.

A third important step, which also suggests that philosophers' intuition talk may not be such a distinctive phenomenon, is made in my "How 'Intuition' Exploded" (Andow 2015a), in which I presented a quantitative study of the use of intuition talk across many academic disciplines and across the period 1900-2009. My primary focus was to examine the "common wisdom" that philosophers now use intuition talk much more than they once did. I confirmed the common wisdom. My main finding, however, was that philosophy is not alone in this regard. The same "explosion" is apparent across the whole academy (and even for English fiction and TIME magazine). I used this to put pressure on the idea that philosophical intuition talk is somehow a special or distinctive phenomenon.

While the results of Andow 2015a are suggestive, the quantitative methods used provide only a fairly blunt tool. I was not able to examine the ways in which different academic disciplines use intuition talk. Although the rise in intuition talk might be a more general phenomenon,

${ }^{6}$ Tallant's discussion focusses intentionally almost entirely on the use of "intuition that" (and similar) as opposed to "intuition of." 
it may still be the case that philosophers have developed a distinctive idiolect and employ intuitions in a distinctive way in their inquiry. As I noted then, in order to address such questions, a more qualitative approach is needed. That's what I try to do here.

\section{Studies}

In the following, I present the results of a study that examines instances of intuition talk in two bodies of text. By "instances of intuition talk" I mean sentences or passages using the following words: "intuition(s)," "intuitive(ly)," "intuit(s)," and "counter-intuitive(ly)."

The first corpus examined is the BASE corpus of spoken academic English. ${ }^{7}$ The BASE corpus contains 160 annotated transcripts of forty lectures from each of four broad categories of academia: arts and humanities, life and medical sciences, physical sciences, and social studies and sciences. ${ }^{8}$ The words "intuition," "intuitive," and related words appear in fifteen of those lectures (three arts and humanities, five social sciences, five physical sciences, and two life sciences). Two categories of usage are not given primary attention here: (i) those made in philosophy lectures and (ii) those (a total of two) made in broken English by a non-native speaker in a lecture in a department called Centre for English Language Teacher Education. The remaining total token instances was twenty-five.

The second corpus examined is a sample of academic research articles. This corpus was compiled for the present study. The corpus contains the text of a number of journal articles from four disciplines: finance, linguistics, law, and psychology. All articles were published in 2010-2011. The corpus contains ten articles from law, psychology, and finance, and nine from linguistics; a total of thirty-nine. ${ }^{9}$

The process for the selection of the four disciplines was as follows. The disciplines were chosen using the figures resulting from my previous studies in Andow 2015a. The earlier article provides figures concerning the

7 The transcriptions used in this study come from the British Academic Spoken English (BASE) corpus (http://www2.warwick.ac.uk/fac/soc/celte/research/base/). The corpus was developed at the Universities of Warwick and Reading under the directorship of Hilary Nesi (Warwick) and Paul Thompson (Reading). Corpus development was assisted by funding from the Universities of Warwick and Reading, BALEAP, EURALEX, the British Academy, and the Arts and Humanities Research Council.

${ }^{8}$ The transcripts in the corpus are annotated. I include only the basic wording used by speakers, replacing pauses with notional punctuation.

9 The intention was to include ten from each of the four disciplines. Unfortunately, an error was made in the corpus creation process, which I discovered only after the analysis was complete. Since the number of token uses across the four disciplines varied considerably, however, this error should not affect the survey. It was not possible to include a tenth article from linguistics in the same way as the original set was selected, since by the time the error was discovered the relevant rankings had changed considerably. 
proportion of articles in the decade 2000-2009 in each discipline indexed by JSTOR that contain at least one token instance of intuition talk. These four disciplines were chosen from among those with the highest proportion of articles engaging in intuition talk. As ranked by proportion engaging in intuition talk, these four disciplines are not the four highestphilosophy is number 1 , finance 2 , linguistics 5 , law 12 , psychology 27 -as consideration was also given to the number of articles published (e.g., folklore was not included on these grounds) and to a desire to include a fairly broad range of disciplines (e.g., business, economics, statistics, marketing, and management were not included on these grounds, as finance had already been selected).

The process for the selection of articles was as follows. JSTOR was used to run a search query for each discipline to return all articles in 2010-2011 indexed by JSTOR containing at least one instance of intuition talk. For each of the four disciplines, these articles were then ranked according to JSTOR's own "Relevance" algorithm (which incorporates the number of citations an article has received by other articles in JSTOR); the chosen articles were those that were ranked highest (any articles that also listed philosophy as a subject area were not included). Selecting the corpus in this way provides some assurances that the articles considered have gained attention in their field. ${ }^{10}$

The approach taken with respect to both corpora is qualitative. In each case, the texts studied were approached with no clear hypotheses in mind. ${ }^{11}$ For each body of text studied, the first step was to isolate all passages containing any instances of intuition talk (to reiterate, this means any word from the following list: "intuition(s)," "intuitive(ly)," "intuit(s)," and "counter-intuitive(ly)"). Selected passages were then compiled in a separate document (one per discipline). The resulting documents were openly coded. On the first reading, uses were simply grouped according to surface similarities. Once this had been done for each document, the texts were read through a second time and coded according to themes that emerged. The coding themes used for each document were allowed to be informed by themes emerging from all the texts studied. The results in the following sections report and illustrate the themes that emerged in each body of text studied. I have also included the proportion of token uses that fall under each theme (ignoring philosophy and a speaker using broken English). I allowed a single token use to be counted under multiple themes where appropriate.

\footnotetext{
${ }^{10}$ All citations within the quotes have been removed or replaced with "[citation]" or similar, for brevity.

${ }^{11}$ As one might in grounded theory approaches in the social sciences, for instance (see Charmaz 2006).
} 


\subsection{Results: BASE Corpus}

Using a basic open coding the following four themes emerged as dominant.

4.1.1. Methodological (48 Percent of Token Uses). Many mentions in disciplines other than philosophy are in a context that precludes their indicating an appeal to intuition in support of a position or claim. Many are explicitly methodological (either detailing an endorsed methodological position or telling us about one that someone else endorses or endorsed). Interestingly, these methodological uses paint a generally negative picture of the status of intuitions in good practice. For example (the emphases are mine in all the examples):

... people are now no longer interested in native speaker intuitions . . we want to give our learners access to what people actually do, not what linguists think they do, or native speakers intuit they do, and I think it's a very good example of practice in our field. (Applied Linguistics)

... most historians considered that it was no longer adequate to rely on intuition, this great idea of empathy and intuition ... this sort of almost mystical belief that [figure in the literature] had. (History)

.. . but it's the kind of vocabulary they need for university level study so that's our subtechnical vocabulary ... we feel this intuitively, but we want we don't want to just take our corpus and go along and say oh that's technical that's subtechnical that's technical ...., that would be too intuitive, we can't do that, we have to have some means of defining what is a technical term and what is a subtechnical term and what is an everyday word. (Centre for English Language Teacher Education)

... how do you know whether it's technical or subtechnical: intuitively. It's always been done intuitively in the past but it's not very satisfactory is it. (Centre for English Language Teacher Education)

4.1.2. Intuition Can Be Misleading (28 Percent of Token Uses). A number of uses indicate that, at least with regard the matter in hand, intuition is misleading in some way. For example:

... now that seems at first glance perhaps counter-intuitive because one has normally grown up with the idea that if you have a highly concentrated market that is consisting of only two or three firms they will in fact be able to wield considerable market power. (Economics)

... and people get in a real muddle with this because of course the wind increases with height, but that means it decreases with pressure, so the sign is often perhaps a bit counter-intuitive. (Meteorology) 
... but remember, the theory of international trade tells us that [fact], that's not intuitively obvious to people. (Economics)

4.1.3. Intuition as Snap Judgement (52 Percent of Token Uses). Some uses seem to indicate that a judgement was not reached using elaborate or extensive reasoning or is intended for easy consumption (which should be reminiscent of Cappelen's observation concerning philosophers' unreflective uses of intuition talk). Some examples of this usage include:

... for those of you who don't like theory, if I put up a model, I'm going to try and explain it intuitively ... to try and ensure that you know maths isn't the overriding thing that's important. (Economics)

. . . but we ought to be intuitively confident that asking a thousand people how they voted, assuming they didn't lie to us, ... that we have a fairly good idea of the result of the election. (Statistics)

. . what I mean by the term of haplotype, I think you'll probably intuitively understand, is you have a series of loci, along a chromosome, linked along a chromosome, then a haplotype is a set of alleles on along those particular ... loci. (Biological Sciences)

Well . . . this quantity intuitively measures the difference between X-bar and what we'd expect, namely, zero. (Statistics)

What is a suitable test statistic? What is it about these things that would lead us to doubt the null hypothesis is true? Well, it's the difference isn't it, intuitively? (Statistics)

4.1.4. Intuition as Epistemically Positive (24 Percent of Token Uses). There are some uses, as Tallant noted in physics, in which saying something is intuitive seems to be used to say something positive about the relevant content. For example:

... one easy way to think of it is that ..., well it's clear intuitively clear that that the ability to swap is going to maintain [the] value of one's currency. (Economics)

One finding that is very clear is that uses of "intuitively" to modify content are very easy to find in the non-philosophy lectures. This is important. As, remember, Cappelen's study found that such uses were very difficult to find in ordinary English. Non-content-related uses in the corpus were far 
outnumbered. Here are two (the only two obvious uses, the first is from a seminar):

It's for you to decide which is most appropriate or if in fact objective forecasting is at all appropriate, it may be that you deem that the demand is so sporadic, so unpredictable, that an intuitive subjective approach to forecasting may be better. ... (Manufacturing)

... how do we communicate the distinction that [name] drew with you between learning and acquisition; explicit learning, which is logical and involves reasoning, versus implicit acquisition, which is intuitive and hopefully automatic. (Applied Linguistics)

Some other minor uses include one of the "getting some intuition" sense that Tallant noted in physics:

... you do have, for the purposes of examinations, to be able to perform such calculations, but, in the longer term, what you need to develop is some intuition about what's going on with these definitions.... (Economics)

And there were also a few uses of "intuition" to denote some sort of faculty or ability, for example:

... we can sketch out the shape... purely by a sort of physical intuition. (Engineering)

... here's a beam vibrating how ... would it sag under gravity. That's a good guess of the shape it will vibrate in for its lowest mode of behaviour. So let's use that as the starting point for the system ... you use sort of common sense, guesses, intuition, whatever you like to call it, to deal with that. (Engineering)

\subsection{Results: Journal Articles}

The results for this corpus are arranged by discipline.

4.2.1. Linguistics. In alphabetical order, the nine articles from linguistics were: Arregi 2010; Boguraev and Neff 2010; Haspelmath 2010; Hunter and Resnik 2010; Kagan 2010; Kim and Baldwin 2010; Nothofer 2010; Wagner 2010; Zhou 2010. The total number of token uses of intuition talk was forty-three. The main themes apparent in these articles were as follows.

First, the terms were dominantly used to talk about content ( 72 percent of token uses in linguistics concerned content, only three obviously modified something other than content). For example: 
This goes against a basic intuition behind virtually all modern linguistic theories, namely that there is a one-to-one mapping between arguments and thematic/grammatical roles. (Arregi 2010, 541)

Things described as intuitive were: notions, ideas, and perceptions (with propositional content); also sequences, strengths, groupings, and interpretations. It should be noted that many of these latter are, on closer inspection, uses modifying content. For example, instances of " $x$ is the intuitive grouping for $y$ " might be better understood by a philosopher were they to be written "it is intuitive that $x$ is the grouping for $y$."

Second, intuitive content is often presented as needing to be accounted for or explained (47 percent of token uses in linguistics). It often seems that it is supposed a good thing to accommodate an intuition, for example:

For a potential explanation for the intuition reported by [author] see the discussion of focus and givenness in [source]. (Wagner 2010, 227)

Third, words like "intuition" are used in hedging roles rarely (only 2 percent clearly functioned as a hedge), and intuitions are seldom presented as misleading (only 7 percent). Rather, it often seems that substitution of "pre-theoretic judgement" or something similar for "intuition" preserves the meaning.

4.2.2. Law. In alphabetical order, the ten articles from law were: Addo 2010; Austin 2010; Braman, Kahan, and Hoffman 2010; Bray 2010; Chehtman 2010; Georgosouli 2010; Marino, Matsusaka, and Zábojník 2010; Roberts and Saunders 2010; Schragger 2009; Van den Steen 2010. Although none of these articles mentions philosophy as a subject area, some draw on literature familiar to philosophers, and certain of the uses are similar. The total number of token uses of intuition talk was 181 . The main themes were as follows.

First, the terms are often used to describe content (46 percent of token uses in law), for example:

Generally speaking, when someone commits a wrong-murder, rape, theft, or fraud, say-we share an intuitive sense that the wrongdoer should be punished. (Braman, Kahan, and Hoffman 2010, 1538)

And these content-related uses are rarely used in obvious hedging roles (2 percent token uses in law), for example:

Intuitively, availability of monetary incentives changes the trade-offs in two ways. (Marino, Matsusaka, and Zábojník 2010, 433) 
Second, there were some uses not associated with content (6 percent of token uses in law): revulsions (Addo 2010), mechanisms (Van den Steen 2010), dimensions (Marino, Matsusaka, and Zábojník 2010), and behaviour (Roberts and Saunders 2010) were all described as intuitive.

Third, that which is intuitive often seems to demand explanation, and explaining or accounting for the intuitive is viewed positively (14 percent of token uses in law), for example:

The conversational thesis is compelling not least because it appeals to our intuitions regarding the moral constitution of the members of the regulatory community and the importance of ensuring that regulation is procedurally efficient. (Georgosouli 2010, 383)

Fourth, perhaps the most dominant theme ( 63 percent of token uses in law) was that intuition talk is used what we might call "descriptively" to say something about what is generally intuitive to people, about which intuitions are innate, or about "human intuitions" (rather than what is intuitive to the researcher), for example:

If humans share highly specific intuitions about justice as a consequence of innate moral mechanisms. . . . (Braman, Kahan, and Hoffman 2010, 1532)

It is suggested that the constructive thesis is preferable to its conversational counterpart because - as the analysis above made plain - it is sophisticated enough to accommodate two fundamental intuitions about regulatory interpretation.... (Georgosouli 2010, 382)

One final point worth noting is that there is a novel (to the present author) sense of "intuition," in two papers (although 8 percent of the total uses in law), which might be associated with the "getting some intuition" sense discussed above (in relation to Tallant's study and the BASE corpus), namely:

Moreover, the results also give some useful intuition on the differences. (Van den Steen 2010, 412)

In order to highlight the basic intuition of our analysis, we start by considering the case where the agent receives no monetary compensation. (Marino, Matsusaka, and Zábojník 2010, 443)

4.2.3. Psychology. In alphabetical order, the ten articles from psychology were: Carr and Steele 2010; Dunn et al. 2010; Erickson, Keil, and Lockhart 2010; Filippova and Astington 2010; Kanngiesser, Gjersoe, and Hood 2010; Kowske, Rasch, and Wiley 2010; Lane, Wellman, and Evans 
2010; Massey, Simmons, and Armor 2011; Mattes et al. 2010; Nock et al. 2010. The total number of token uses of intuition talk was seventy-nine. The main themes were as follows.

First, the use of the terms to do something other than modify content was very common (57 percent of token uses in psychology). There was talk of intuitive decision making, abilities, learning, reasoning, capacities, mechanisms, portion, functions, processes, systems and biases. (This might make psychology look rather different from other fields in terms of whether intuition talk is used to talk about content. That isn't the main message to be taken from this, however. To see this, consider the second main theme that emerged.) $)^{12}$

Second, the vast majority of uses were descriptive ( 81 percent of token uses in psychology), that is, made claims about participants' (or humans') minds (rather than the researchers' or psychologists' intuitions), for example:

The somatic marker hypothesis proposes that emotional biasing signals emerging from the body influence intuitive decision making. (Dunn et al. 2010, 1835)

An anthropomorphism hypothesis is intuitively appealing; even adults tend to think of nonhuman beings, such as God, as human-like. (Lane, Wellman, and Evans 2010, 1476)

This is important, as all the non-content-related uses were descriptive and many of the descriptive claims are about some sort of faculty or capacity (50 percent of token uses in psychology). In Dunn et al. 2010, for example, there is a lot of talk of "intuitive decision making" (eight token uses); this is some sort of capacity, faculty, or group of psychological mechanisms that delivers decisions. There is also talk of "intuition" as a faculty, for example:

... the interpretation of complex intentions, motivations, and attitudes is not a matter of simple intuition. (Filippova and Astington 2010, 925)

Some other minor points are worth noting. First, some uses, one might be tempted to think, signal an appeal to intuition (this was far from the dominant usage), for example:

${ }_{12}$ Another reason not to take this at face value is that in a number of cases, although at the level of syntax "intuitive" may modify something other than content, for example, the noun "function," what is actually being said makes it clear that a proposition is what is being talked about using intuition talk, for example: "Indeed, although formal religious doctrine may attribute radically nonhuman, counterintuitive capacities to deities (e.g., total omniscience)" (Lane, Wellman, and Evans 2010, 1476). 
Attractiveness judgments yielded a counterintuitive result, in that they were negatively associated with election outcomes. (Mattes et al. 2010, 51)

Despite offering an intuitively appealing mechanism for social change, the problem of generations in research has been lamented for decades. (Kowske, Rasch, and Wiley 2010, 268)

Second, I found no obvious uses as a hedging term. This is likely due to the descriptive focus.

4.2.4. Finance. In alphabetical order, the ten articles from finance were: Alexander et al. 2010; Becsi 2010; Bettis et al. 2010; Chui, Titman, and Wei 2010; Foley and Greenwood 2010; Guttman, Kadan, and Kandel 2010; Kolari and Pynnönen 2010; McLean 2010; Morellec and Schürhoff 2010; and Rauh and Sufi 2010. The total number of token uses of intuition talk was twenty-nine. The main themes were as follows.

First, use in finance was clearly content focused (62 percent of token uses in finance, only three uses obviously modified something other than content). Two dominant uses are "intuitively, $p$ " and "intuition/intuitive that."

Second, a third dominant use is to indicate something one can do (or a case one can consider) to help one grasp a difficult idea (34 percent of token uses in finance), for example:

The intuition of this latter result is evident if one considers a bank creditor with a claim that represents a very large fraction of the borrower's capital structure. In such a situation, the bank has less of an incentive to liquidate a risky borrower, given that the bank's large claim benefits relatively more from risktaking than a smaller claim. (Rauh and Sufi 2010, 4257)

To provide some intuition for the process by which firms become widely held, we briefly consider some examples that make evident that the percentage of shares outstanding held by blockholders can change for two reasons: either blockholders buy or sell, or the firm issues or repurchases outside equity. (Foley and Greenwood 2010, 1238)

This use is similar to the novel use we saw in linguistics. It seems that "intuition" in this sense has to do with easy consumption.

In finance, remarks about whether something a researcher asserts are "intuitive" or "counter-intuitive" are not making the sorts of descriptive claims we saw in law and psychology but rather saying something about the researcher and/or their audience. These remarks also seem to be geared at helping the reader understand and helping them avoid misunderstandings, for example: 
While it may seem intuitive that idiosyncratic risk is only relevant if the arbitrageur is undiversified, in fact. . . . (McLean 2010, 884)

While an increase in event-period variability is considered to be intuitive [citation], [authors] show that cross-sectional variation in the effects of events always produces event-induced variance. (Kolari and Pynnönen 2010, 3998)

There are two cases where "intuition" appears to be indicating something in favour of accepting the relevant proposition:

The proof is immediate. Intuitively, the manager balances the marginal benefit from a higher short-term price with the cost of underinvestment. A higher weight on short-term stock-based compensation ... induces him to underinvest more. (Guttman, Kadan, and Kandel 2010, 4465)

Furthermore, their coefficient estimates have signs that are consistent with our a priori intuition. (Alexander et al. 2010, 4444)

And there are a couple of uses that appear to hedge, for example:

Intuitively, the left-hand side of Equation (9) can be viewed as an "adjusted" return around the interim news date, where the adjustment takes into account the prediction effect and any other outcome probability revisions. (Alexander et al. 2010, 4429)

Intuitively, higher unit costs require higher marginal productivity that occurs when funds decline. (Becsi 2010, 194)

\subsection{Results: Summary}

A neat summary and comparison with Cappelen and Tallant's qualitative findings is not easy to give. Nevertheless, here is my best attempt at summarizing. (I'll address the relation between the present study and Andow 2015a in the next section.)

First, although there is no single usage of "intuition," "intuitive," and so on, in the BASE corpus, the patterns of usage are similar to those Cappelen finds in philosophy texts and those Tallant finds in physics texts, and reasonably dissimilar to the use Cappelen notes in ordinary English. I say this because "intuitive" and similar words are commonly used in the BASE corpus to talk about content, whereas Cappelen claimed this was the exception in ordinary English. These words are often used to indicate that a judgement was not reached using elaborate or extensive reasoning or are used to indicate that the answer is intended for quick and easy understanding. Some of these uses are as a hedging term, some are not; I 
am uncertain about most. Looking back, a large number could be understood in the sense of pre-theoretic, although I have difficulty making clear judgements about whether they should be interpreted this way from the text. There are a number of uses, in economics and engineering, of "intuition" and "physical intuition" to talk about a faculty or ability. The uses of intuition talk which imply that intuitions are being treated as something epistemically positive/negative are approximately evenly balanced (although the negative statements occur primarily in two disciplines, history and linguistics). As I have noted, even if such ways of speaking are rare in contemporary philosophy, this was fairly common in the past.

Second, use across finance, psychology, law, and linguistics is varied. Clearly, the terms are not used simply in same the way as they are in ordinary English - according to Cappelen at least. There are definite differences between the academic fields. Use in all four disciplines, however, seems to have more in common with the uses Cappelen identifies in philosophy than those he identifies in ordinary English. Again, there was a dominant use to talk about content. Often this is used in the senses Cappelen notes in philosophy: similar to "pre-theoretic," indicating that a judgement is reached without lengthy consideration or indicating that content is to be easily consumed. Where seemingly used to talk about something other than content, that use is often easily assimilated either to talk about intuition as a capacity or to talk about the intuitiveness of some content (for both these uses, the passages from psychology provide the best examples). Obvious use as a hedge is rare. However, as Cappelen notes $(2012,77)$, hedging uses are difficult to identify with any certainty, and for both corpora examined I took a conservative approach in identifying token uses as hedges (it is possible that many of the uses, in the eyes of those familiar with the respective fields, would be clear cases of a hedge). Another novel (to this author) use appeared, this time in law and finance: "to understand the intuition behind $x$ " and similar phrases. This seems connected with the "building intuition" sense Tallant observed in physics. The aim in such passages often seems to be aimed at ensuring comprehension through illustration or examples without appeal to what might be called "official grounds," for example, proofs, formal work, or data. ${ }^{13}$ In some cases, the author seems to provide a claim's being intuitive as some sort of reason to accept either the claim itself or some theory it supports. Such cases are rare, however.

\section{Conclusions and Hypotheses}

What does all this tell us about the distinctiveness of philosophical methods? And what implications do these results have for evaluative and ameliorative methodology?

${ }^{13}$ My instinct is that this is close to the sense of "pumping intuitions" as sometimes used by philosophers.

(C) 2015 The Author. Metaphilosophy published by Metaphilosophy LLC and John Wiley $\&$ Sons Ltd 
The findings above are made only tentatively. Nonetheless, it is clear that they lend no particular support to the idea that philosophers' intuition talk is distinctive, and in turn they lend no support to the idea that there is something distinctive about philosophers' use of intuitions themselves. When put together with the results of Andow 2015a, which suggest that a rise in intuition talk is a fairly general phenomenon, this case is even stronger. The emerging picture is that there is a rising trend in intuition talk and that intuition talk in different academic disciplines, while far from completely homogeneous, shares some important common themes. I certainly don't think the current results challenge the conclusion (which Cappelen reaches) that studying philosophers' intuition talk lends no support to the idea that philosophers rely on intuitions as evidence in some distinctive way.

The results of this preliminary study do seem to suggest that the use of intuition talk is surprisingly similar across academia. In particular, the results suggest the following hypothesis: There is a common core of uses within academic English that is not present in ordinary English (or perhaps is marginally present). Call this hypothesis Common Core. The uses that I hypothesise as being part of this common core are as follows.

1. The dominant use of words such as "intuition" is to describe contents, for example, claims or hypotheses.

2. A prevalent use of intuition talk is to talk about faculties that deliver those contents, for example, "intuition tells us that. ..."

3. A prevalent use of intuition talk is in passages that are geared towards giving the audience a way to understand a theory or position where "the intuition" or "the intuitive" is not associated with evidential/theoretical/formal support for that theory or position.

4. A prevalent use of intuition talk is to talk about something of methodological importance. The precise nature of the importance seems to differ by domain. In some domains, reliance on intuition is a symptom of the ancien régime (history/certain language-based disciplines); in some, it serves as a starting point (physics/ engineering); in others, it is often relied upon (some linguistics); in some, intuitions need explaining (law). The methodological importance of intuitions is less obvious in psychology probably because the focus of intuition talk in psychology is descriptive-looking at the intuitive capacities of participants.

This is but a hypothesis suggested by the data. To test Common Core, further corpus-based studies will be appropriate. In particular, it will be useful to examine ordinary English intuition talk, for example, to assess Cappelen's claims about ordinary usage, to examine a larger sample of 
academic intuition talk for evidence of this common core, and to compare these findings. ${ }^{14}$

However, the fact that this hypothesis emerges is interesting. Of particular interest is the third point: that intuition talk often appears in passages that are geared towards giving the audience a way to understand a theory or position. ${ }^{15}$ This suggests that intuitions may play an important role throughout academia in explanatory contexts and perhaps especially pedagogical contexts. ${ }^{16}$

This is interesting because methodologists have typically not focused on the use of intuitions in this sort of context. The typical focus on intuitions has been a focus on intuitions vis-à-vis any justificatory role they might play in what might be called the context of justification. Other roles have been recognised as being potentially important; for example, Cappelen notes that he says nothing about an alternative context that might be called the "context of discovery." The idea that intuitions have a big role in explanation is not, however, one that is captured easily by thinking about the use of intuitions in either a context of discovery or a context of justification. The use of intuitions to explain is not geared to providing support for positions (as they would when used in a context of justification), and intuitions are not used to help construct new ideas and theories or as inspiration (as they would when used in a context of justification). To clarify, there are of course varieties of explanation that are clearly within a context of justification. If I ask you to explain why a theory is true, you will adduce reasons to believe the theory. That, however, is not the variety of explanation I have in mind (nor the one

${ }^{14}$ Further corpus-based work could be fruitfully supplemented by interviews with academics from various disciplines. It is perhaps worth noting that I would not expect the use of intuitions in explanation to be uniform across academia. Understanding a theory or position typically enables one to go on to do various other things. Once one has an intuitive understanding of a certain theory one may be better able to use it regardless of whether that intuitive understanding constitutes part of the evidence for the theory; for example, you might be better able to predict the distribution of certain data sets, or perhaps to predict how stakes will affect knowledge attributions. And, since the types and uses of theories differ from discipline to discipline, the use of intuition and "intuition" should probably be expected to show important differences.

15 The lectures in the BASE corpus are mostly lectures on undergraduate courses. So this use in explanation may have been particularly notable.

${ }^{16}$ The idea that intuitions often play this role also makes sense of a number of Cappelen's findings. Cappelen examines a number of supposed paradigmatic uses of intuition in philosophical argument, for example, Chalmers's Zombie argument in The Conscious Mind. Chalmers finds that often the claims that are supposed to be the intuitions are not treated as having any default justificatory status; rather, further argument is offered in favour of the claims (1996, 130-87). This is a somewhat surprising finding. If intuitions are supposed to be our evidence, what are philosophers doing arguing for them? The Common Core hypothesis can make some sense of this finding, however. Drawing your audience's attention to claims which you hope they find intuitive is a good way to get your audience to grasp the contours of your theory whether or not those claims actually help support the theory. It would then make sense to go on to provide support for those claims, provide arguments, and so on. 
suggested by the data). Rather, the suggested role is distinctively communicative, used to help others come to understand your position or theory, or its implications. Intuition can play this role even if it lends no support to the theory and plays no part in the creation of that theory.

So, while the primary purpose of the present study is descriptive, I think that the findings should help shape more evaluative and/or ameliorative methodological projects. The upshot is not revolution among metaphilosophers - as Cappelen urges should result from his descriptive efforts. For example, the present findings do not show that it is a mistake for methodologists to focus upon the role of intuitions and whether intuitions can play an evidential role in philosophy (for philosophical methods may use intuitions both in explanation and in justification). The present results do, however, suggest a novel, and potentially fruitful, avenue for methodologists to explore: the role of intuitions in getting an audience to understand a position, in providing explanations, and in pedagogical contexts in philosophy (and potentially elsewhere).

For instance, there is an important debate to be had in evaluative methodology about whether use of intuitions in explanatory contexts is a positive thing or whether it might be problematic.

On the one hand, the helpful and educative nature of such explanatory appeals to intuitions (as hypothesized by Common Core) might be seen as a positive thing. Moreover, when intuitions are used outside the context of justification, it might be much less important whether what people find intuitive is affected by factors that are irrelevant to the truth (for example, framing effects and demographic effects). So, for instance, it might be that the methodological challenge to the use of intuitions in philosophy from the "negative programme" in experimental philosophy does not apply, or applies to a much lesser extent, to the use of intuitions in explanatory contexts.

On the other hand, however, there are perhaps reasons to think that using intuitions in explanation could still be problematic. It is tempting to think that their use in a context of explanation would prevent intuitions from leading philosophers astray. So long as intuitions are not used to provide support for positions, one might think, then intuition cannot mislead philosophers. This is not obviously the case, however. First, intuitive understandings can be misunderstandings and could, for instance, be exploited to give false positions a veneer of respectability (since understanding a position is a precondition for accepting a theory). Second, an intuitive explanation of a theory may affect one's responsiveness to reasons. Suppose I present a theory to a class. I present the theory with no appeal to intuitions - no intuitions are part of the support for the theorynonetheless, I present the theory in a very intuitive way. It is likely it will take less evidence, fewer/weaker reasons, or weaker justification to persuade the class that the theory is true than had I explained it in a manner less appealing to my students' intuitions. So there might be a worry that 
exploiting intuitions in the explanation of positions could be somewhat coercive. So long as intuitions can affect how likely we are to accept positions, there is a potential source of concern.

In any case, if Common Core is right, then an important thing for evaluative methodology to do would be to ask whether using intuitions in explanatory contexts is a good or a bad practice. In this project, as in other evaluative projects, it would seem that the empirical science of intuitive judgement would have important contributions to make.

Department of Philosophy

University of Reading

Whiteknights

Reading, Berkshire RG6 6AH

United Kingdom

jamesandow@gmail.com

\section{Acknowledgments}

Thanks to a number of anonymous referees, Jules Holroyd, Jonathan Tallant, and audiences in Birmingham, Nottingham, and Liverpool for helpful comments. This article draws on a chapter of my AHRC-funded $\mathrm{Ph} . \mathrm{D}$. thesis; the research was conducted while I was a Ph.D. student in Nottingham.

\section{References}

Abernathy, C., and R. M. Hamm. 1995. Surgical Intuition: What It Is and How to Get It. Philadelphia: Hanley and Belfus.

Addo, M. 2010. "Practice of United Nations Human Rights Treaty Bodies in the Reconciliation of Cultural Diversity with Universal Respect for Human Rights." Human Rights Quarterly 32, no. 3:601-64.

Alexander, C. R., M. A. Chen, D. J. Seppi, and C. S. Spatt. 2010. "Interim News and the Role of Proxy Voting Advice." Review of Financial Studies 23, no. 12:4419-54.

Andow, J. 2015a. "How 'Intuition' Exploded.” Metaphilosophy 46, no. 2 (April): 189-212.

- 2015b. "Thin, Fine, and with Sensitivity: A Metamethodology of Intuitions." Review of Philosophy and Psychology (online first): 1-21.

Antony, L. 2012. "Different Voices or Perfect Storm: Why Are There So Few Women in Philosophy?" Journal of Social Philosophy 43, no. 3 (Fall): 227-55.

Arregi, K. 2010. "Ellipsis in Split Questions." Natural Language and Linguistic Theory 28, no. 3:539-92.

Austin, L. M. 2010. "Person, Place, or Thing? Property and the Structuring of Social Relations." University of Toronto Law Journal 60, no. 2: 445-65. 
Becsi, Z. 2010. "Does Wealth Imply Secularization and Longevity?" Journal of Money, Credit and Banking 42, no. 1:189-202.

Bettis, C., J. Bizjak, J. Coles, and S. Kalpathy. 2010. "Stock and Option Grants with Performance-Based Vesting Provisions." Review of Financial Studies 23, no. 10:3849-88.

Boguraev, B., and M. Neff. 2010. "A Framework for Traversing Dense Annotation Lattices." Language Resources and Evaluation 44, no. 3:183-203.

Braman, D., D. Kahan, and D. Hoffman. 2010. "Some Realism About Punishment Naturalism." University of Chicago Law Review 77, no. 4:1531-609.

Bray, S. L. 2010. "Preventive Adjudication." University of Chicago Law Review 77, no. 3 (Summer): 1275-334.

Cappelen, H. 2012. Philosophy Without Intuitions. Oxford: Oxford University Press.

Carr, P. B., and C. M. Steele. 2010. "Stereotype Threat Affects Financial Decision Making." Psychological Science 21, no. 10:1411-16.

Chalmers, D. J. 1996. The Conscious Mind: In Search of a Fundamental Theory. Oxford: Oxford University Press.

Charmaz, K. 2006. Constructing Grounded Theory: A Practical Guide Through Qualitative Analysis. London: Sage.

Chehtman, A. 2010. "The Extraterritorial Scope of the Right to Punish." Law and Philosophy 29, no. 2:127-57.

Chui, A. C. W., S. Titman, and K. C. J. Wei. 2010. "Individualism and Momentum Around the World." Journal of Finance 65, no. 1:361-92.

Dunn, B. D., H. C. Galton, R. Morgan, D. Evans, C. Oliver, M. Meyer, R. Cusack, A. D. Lawrence, and T. Dalgleish. 2010. "Listening to Your Heart." Psychological Science 21, no. 12:1835-44.

Erickson, J. E., F. C. Keil, and K. L. Lockhart. 2010. "Sensing the Coherence of Biology in Contrast to Psychology: Young Children's Use of Causal Relations to Distinguish Two Foundational Domains." Child Development 81, no. 1:390-409.

Filippova, E., and J. W. Astington. 2010. "Children's Understanding of Social-Cognitive and Social-Communicative Aspects of Discourse Irony." Child Development 81, no. 3:913-928.

Foley, C. F., and R. Greenwood. 2010. "The Evolution of Corporate Ownership After Ipo: The Impact of Investor Protection." Review of Financial Studies 23, no. 3:1231-60.

Georgosouli, A. 2010. "Regulatory Interpretation: Conversational or Constructive?" Oxford Journal of Legal Studies 30, no. 2:361-84.

Guttman, I., O. Kadan, and E. Kandel. 2010. "Dividend Stickiness and Strategic Pooling." Review of Financial Studies 23, no. 12:4455-95.

Hammond, K. R. 1996. Human Judgment and Social Policy: Irreducible Uncertainty, Inevitable Error, Unavoidable Injustice: New York: Oxford University Press. 
Haspelmath, M. 2010. "The Interplay Between Comparative Concepts and Descriptive Categories (Reply to Newmeyer)." Language 86, no. 3:696-99.

Hunter, T., and P. Resnik. 2010. "Exploiting Syntactic Relationships in a Phrase-Based Decoder: An Exploration." Machine Translation 24, no. 2:123-40.

Kagan, O. 2010. "Genitive Objects, Existence and Individuation." Russian Linguistics 34, no. 1:17-39.

Kanngiesser, P., N. Gjersoe, and B. M. Hood. 2010. "The Effect of Creative Labor on Property-Ownership Transfer by Preschool Children and Adults." Psychological Science 21, no. 9:1236-41.

Kasaki, M. Unpublished. "Enriching the Framework of Experimental Philosophy."

Kim, S., and T. Baldwin. 2010. "How to Pick Out Token Instances of English Verb-Particle Constructions." Language Resources and Evaluation 44, no. 1:97-113.

Kolari, J. W., and S. Pynnönen. 2010. "Event Study Testing with CrossSectional Correlation of Abnormal Returns." Review of Financial Studies 23, no. 11:3996-4025.

Kowske, B., R. Rasch, and J. Wiley. 2010. "Millennials' (Lack of) Attitude Problem: An Empirical Examination of Generational Effects on Work Attitudes." Journal of Business and Psychology 25, no. 2:265-79.

Lane, J. D., H. M. Wellman, and E. M. Evans. 2010. "Children's Understanding of Ordinary and Extraordinary Minds." Child Development 81, no. 5:1475-89.

Ludwig, K. 2010. "Intuitions and Relativity." Philosophical Psychology 23, no. 4:427-45.

Marino, A. M., J. G. Matsusaka, and J. Zábojník. 2010. "Disobedience and Authority." Journal of Law, Economics, and Organization 26, no. 3 : 427-59.

Massey, C., J. P. Simmons, and D. A. Armor. 2011. "Hope over Experience." Psychological Science 22, no. 2:274-81.

Mattes, K., M. Spezio, H. Kim, A. Todorov, R. Adolphs, and R. M. Alvarez. 2010. "Predicting Election Outcomes from Positive and Negative Trait Assessments of Candidate Images." Political Psychology 31, no. 1:41-58.

McLean, R. D. 2010. "Idiosyncratic Risk, Long-Term Reversal, and Momentum." Journal of Financial and Quantitative Analysis 45, no. 4:883-906.

Morellec, E., and N. Schürhoff. 2010. "Dynamic Investment and Financing under Personal Taxation." Review of Financial Studies 23, no. $1: 101-46$.

Nock, M. K., J. M. Park, C. T. Finn, T. L. Deliberto, H. J. Dour, and M. R. Banaji. 2010. "Measuring the Suicidal Mind." Psychological Science 21, no. 4:511-17. 
Nothofer, B. 2010. "The Fish and the Loom: Toward a United Semantic Reconstruction." Oceanic Linguistics 49, no. 1:144-62.

Overton, J. A. 2013. "Explain' in Scientific Discourse.” Synthese 190, no. 8:1383-405.

Pust, J. 2000. Intuitions as Evidence. London: Garland.

- 2014. "Intuition." In The Stanford Encyclopedia of Philosophy, Fall 2014 edition, ed. E. N. Zalta. At http://plato.stanford.edu/archives/ fall2014/entries/intuition/

Rauh, J. D., and A. Sufi. 2010. "Capital Structure and Debt Structure." Review of Financial Studies 23, no. 12:4242-80.

Roberts, P., and C. Saunders. 2010. "Piloting Ptwi-A Socio-Legal Window on Prosecutors' Assessments of Evidence and Witness Credibility." Oxford Journal of Legal Studies 30, no. 1:101-41.

Saul, J. 2013. "Implicit Bias, Stereotype Threat, and Women in Philosophy." In Women in Philosophy: What Needs to Change? edited by K. Hutchinson and F. Jenkins, 39-60. Oxford: Oxford University Press.

Schragger, R. 2009. "Rethinking the Theory and Practice of Local Economic Development." University of Chicago Law Review 77, no. 1 (Winter): 311-39.

Stich, S., and W. Buckwalter. 2014. "Gender and Philosophical Intuitions." In Experimental Philosophy, edited by J. Knobe and S. Nichols, 2:307-46. Oxford: Oxford University Press.

Tallant, J. 2013. "Intuitions in Physics." Synthese 190, no. 15:2959-80.

. 2015. "Metaphysics, Intuitions and Physics." Ratio 28, no. 3:286301.

Van den Steen, E. 2010. "Disagreement and the Allocation of Control." Journal of Law, Economics, and Organization 26, no. 2:385-426.

Wagner, M. 2010. "Prosody and Recursion in Coordinate Structures and Beyond." Natural Language and Linguistic Theory 28, no. 1:183-237.

Weinberg, J., S. Nichols, and S. Stich. 2001. "Normativity and Epistemic Intuitions." Philosophical Topics 29, nos. 1-2:429-60.

Williamson, T. 2007. The Philosophy of Philosophy. Oxford: Blackwell. Zhou, C. 2010. "Probability Logic of Finitely Additive Beliefs." Journal of Logic, Language and Information 19, no. 3:247-82. 